\title{
MOMIAS Y HUESOS EN LA NECRÓPOLIS DEL ESPIGÓN (PUNTALLANA, LA PALMA). ESTUDIO BIOANTROPOLÓGICO PRELIMINAR DE UNA CULTURA DESAPARECIDA
}

\author{
Nuria Álvarez Rodríguez¹, Antonio Moreno González² \\ y Jorge Pais Pais ${ }^{3}$
}

\section{Resumen:}

El Barranco del Espigón ocupa un lugar sobresaliente dentro de la etapa prehispánica palmera debido al hallazgo de una importante necrópolis en la que aparecieron restos humanos momificados, siendo estos los únicos de estas características que hoy en día se conoce su procedencia exacta. Este artículo intentará hacer un breve recorrido sobre las formas de vida de los benahoaritas en el Barranco del Espigón así como un pequeño estudio preliminar de los restos óseos humanos encontrados.

\section{Palabras claves.}

La Palma, Puntallana, arqueología, yacimiento funerario, momia, bioantropología.

\section{Abstract:}

El barranco del Espigón holds a prominent place within prehispanic age, in La Palma, due to the discovery by an important necropolis which appeared mummified human remains, these being the only ones with these features nowdays it knows their exact origin. This article will try to make a brief rout above ways on life of "Benahoaritas" in El Barraco del Espigón and make a small preliminary study about human bond found.

\section{Key words:}

La Palma, Puntallana, archeology, burial site, mummy, bioanthropology.

\footnotetext{
1 Alumna de doctorado en la Universidad de La Laguna y colaboradora en el Museo Arqueológico Benahoarita. Correo electrónico: nuriaalvarezrodriguez@gmail.com.

2 Odontólogo colaborador en el Museo Arqueológico Benahoarita.

3 Inspector de Patrimonio en la isla de La Palma.
}

Revista Otarq - ISSN 2530-4933

Vol. 1 2016, pp. 47-64 


\section{Introducción}

Benahoare, nombre que recibe la isla de La Palma en época prehispánica, estaba dividida en 12 demarcaciones territoriales o bandos independientes cuyos datos fueron aportados por el religioso franciscano J. Abreu Galindo: Aridane, Tijuya, Guehebey-Tamanca, Ahenguareme, Tigalate-Mazo, Tedote-Tenibucar, Tenagua, Adeyahamen, Tagaragre, Tagalguen, Tixarafe, Aceró. Sus límites están claros en algunos de los casos, Ilegando a coincidir con municipios actuales, pero en otros hay bastantes dudas por que las fuentes no aportan ningún tipo de información. Estos cantones estaban ocupados por los Benahoaritas, antiguos habitantes de La Palma.

Al frente de cada uno de los bandos independientes se encontraba uno, dos y hasta tres capitanes que siempre eran hermanos. Sin embargo, en algunos pasajes de las crónicas de J. Abreu Galindo parece desprenderse la existencia de otras subdivisiones que podrían corresponderse con otros bandos independientes o, más probablemente, con zonas que gozaban de cierta autonomía de una demarcación territorial de mayor entidad.

Las fuentes etnohistóricas no ofrecen ningún tipo de datos sobre los órganos de gobierno que regían sus destinos, ni siquiera de su estratificación social. No obstante, la existencia de capitanes al frente de los distintos cantones, la presencia de cuerpos momificados y una serie de objetos de adorno y otros objetos de gran suntuosidad, nos dan pie a pensar que existían una serie de personas de alto rango cuya consideración e influencia sobre el resto de la comunidad sería reconocida por todos. De ello podemos colegir que sus decisiones tendrían un peso decisivo entre sus vecinos y que tales cuestiones se dilucidarían en una serie de asambleas que tendrían lugar en recintos especialmente construidos al efecto, como pueden ser un buen número de grandes construcciones de muros de piedra seca que aparecen dispersas por toda la orografía insular y que hemos denominado espacios sagrados, puesto que en ellos no sólo se tratarían cuestiones mágico religiosas, sino otras más mundanas que afectarían a la vida cotidiana de los habitantes de cada demarcación territorial (J. Pais Pais et al., 2010).

Las fuentes escritas nos ofrecen una rica información sobre otros ámbitos de la vida de los aborígenes palmeros pero muchas veces hay que tomarla con cautela. Sobre el mundo de la muerte, contamos con ciertas noticias de gran importancia que nos habla sobre el tratamiento efectuado al difunto. Esto será mencionado con posterioridad.

\section{Objetivo}

Con este trabajo se pretende dar a conocer una cultura, hoy desaparecida y desconocida para el ámbito fuera de las islas Canarias. Para ello se hablará de 
cómo vivían los antiguos pobladores de una zona concreta de la isla de La Palma y como realizaban sus prácticas y rituales funerarios. En este último punto, el trabajo se centrará en el estudio de los restos momificados y esqueletizados de forma preliminar ya que forma parte de un estudio no concluso.

\section{La zona arqueológica del Barranco del Espigón (Puntallana)}

El tramo medio e inferior del Barranco del Espigón, en la zona de Martín Luis (municipio de Puntallana) constituye una interesante zona arqueológica, tanto por la cantidad como por la variedad de yacimientos arqueológicos que alberga. Este tramo del barranco se ubica en la zona de transición entre el cardonal y los bosques termófilos. La vegetación arbustiva alcanza una densidad inusitada que conforma una maraña impenetrable que dificulta sobremanera el tránsito por las laderas de la margen izquierda del barranco, donde se concentra la mayor densidad de yacimientos arqueológicos. Las especies vegetales más abundantes son las retamas (Retama monosperma), cornical (Periploca laevigata), tasaigos (Rubia fruticosa), tajinastes (Gén. Echium), incienso (Artemisia thuscula), vinagreras (Rumex lunaria), etc. De los árboles típicos de los bosques termófilos sólo se conservan ejemplares aislados de palmeras (Phoenix canariensis), dragos (Dracaena draco) y sabinas colgadas (Juniperus phoeniceae) de los riscos más inaccesibles. Finalmente, también nos encontramos con ejemplares de pinos (Pinus canariensis) que, sin duda, antaño fueron mucho más abundantes de lo que podemos apreciar en la actualidad (Fig. 1).

Fig. 1.

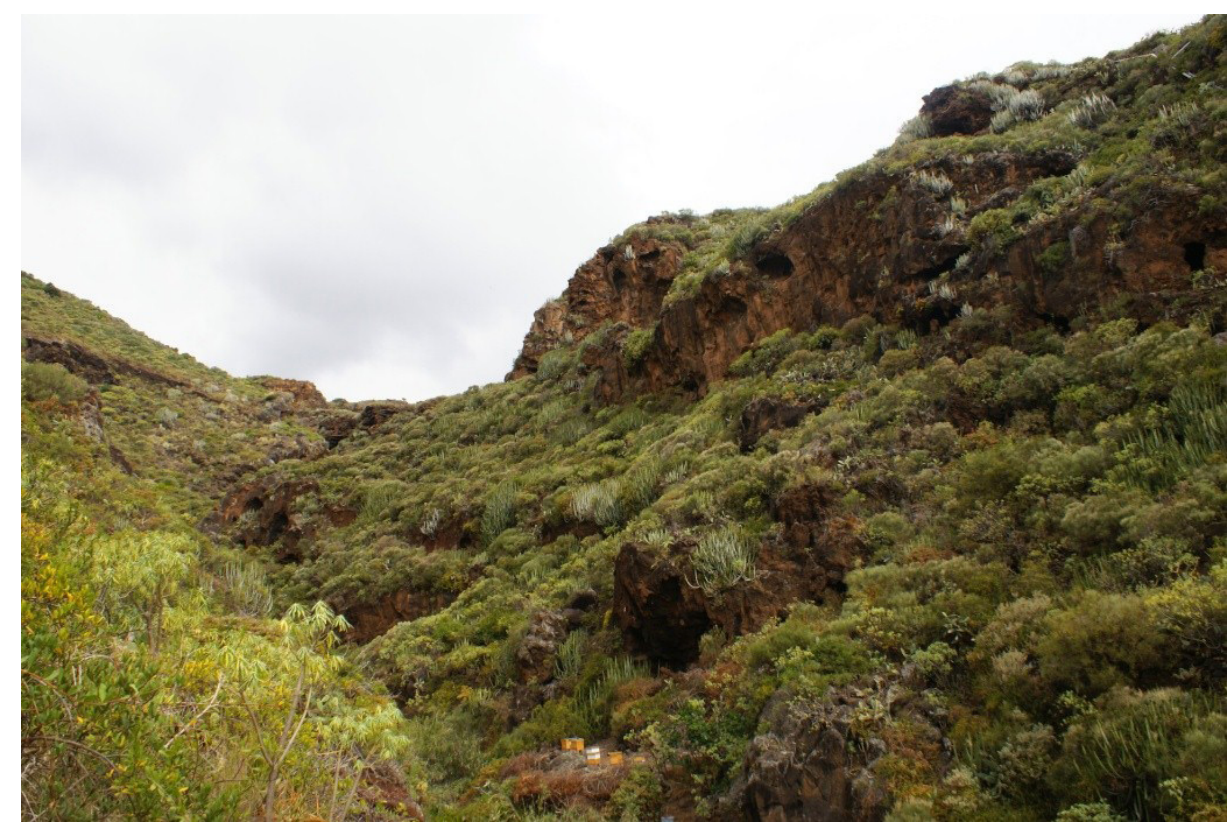


Por tanto, la abundancia de pastizales, la benignidad del clima y la proximidad del mar, de donde extraían abundantes recursos alimenticios en la época estival, permitieron una gran concentración de benahoaritas desde la Fase Cerámica II ${ }^{4}$ (año 400 d. C) hasta la conquista de la isla a finales del siglo XV (Fase Cerámica IV), como mínimo. Estamos absolutamente convencidos, en cuanto se realice la Carta Arqueológica de estos parajes, de que los asentamientos más antiguos se remontan a la primera arribada a la isla en torno al siglo II a. C. (Fase Cerámica I).

Las prospecciones superficiales llevadas a cabo nos hablan de un intensivo poblamiento en las numerosas cuevas naturales que se abren a ambos márgenes del Barranco, si bien en las inmediaciones de la necrópolis, la gran mayoría de las cuevas de habitación se sitúan en la margen derecha. Y, a pesar de que los yacimientos han sido expoliados, en su gran mayoría, aún se puede apreciar la riqueza de los asentamientos si tenemos en cuenta la abundancia de fragmentos de cerámica de todas las fases conocidas en Benahoare, la riqueza y variedad de la industria lítica elaborada en basalto, los numerosos fragmentos óseos machacados de su fauna doméstica (cabras, ovejas y cochinos), la ingente cantidad de conchas marinas (lapas, burgados, púrpuras, etc.) y las gruesas capas de cenizas que recorren la estratigrafía que ha quedado al descubierto.

La zona donde se ubica la famosa momia de la necrópolis del Espigón reúne una serie de condiciones medioambientales que lo convierten en ideal para el asentamiento permanente de los antiguos palmeros. Su economía, fundamentalmente pastoril, encontraba abundantes y jugosos pastizales durante la mayor parte del año. Cuando estos empezaban a escasear, a inicios del verano, existían rutas naturales, de fácil acceso, que les permitían subir a los campos de pastoreo de alta montaña en los bordes de la Caldera de Taburiente. Además, la proximidad de la costa les concedía el privilegio de aprovechar sus recursos alimenticios en cualquier momento, especialmente en la época estival, cuando escaseaban otro tipo de viandas. Por tanto, los moradores de este poblado de cuevas tenían bien cubierto el suministro de cuatro de sus alimentos esenciales: la carne, la leche, el pascado y el marisco. A ello debemos añadir la facilidad de las comunicaciones con otros parajes del cantón de Tenagua al estar emplazado en el centro geométrico del mismo. También tenían asegurado el suministro de agua, que es otro de los parámetros primordiales para explicar la distribución de los principales asentamientos benahoaritas. En este sentido, y en el estado actual de la investigación arqueológica, desconocemos la existencia de fuentes en el Barranco del Espigón, si bien a escasa distancia hacia el sur se encuentra el

4 Para la isla de La Palma contamos con la suerte de que la cerámica aborigen actúa como un fósil guía siendo una constante en los yacimientos arqueológicos pudiendo establecer así fechas relativas. Esto solo lo podemos apreciar en esta isla. Las fases van desde la I que corresponden con las primeras Ilegadas de poblaciones a la isla en un momento no muy exacto (en torno a los siglo II-I a.C.), pasando por la II, III con sus consiguientes subfases, hasta llegar a la IV, momento en el que se produce la conquista Canaria. 
Barranco del Agua, donde este líquido tan preciado es abundante y constante a lo largo de todo el año.

Las cuevas naturales de habitación presentan unas inmejorables condiciones de habitación en cuanto a dimensiones, luminosidad, exposición (en su inmensa mayoría están expuestas hacia el sur) y protección contra las inclemencias del tiempo. La intensidad del doblamiento prehispánico se pone de manifiesto si tenemos en cuenta que absolutamente todas las cavidades (cuevas, covachas y cejos) fueron habitadas por los benahoaritas.

La importancia del poblado del Barranco del Espigón queda resaltada, además por la existencia de una nueva necrópolis, por un posible almogarén y un conjunto de canalillos y cazoletas. El yacimiento funerario es de un enorme interés porque se encontraba prácticamente intacto y parece que cuenta con varias capas de deposición de los cuerpos y un ajuar funerario que consistía en fragmentos de cerámica muy peculiares, piezas líticas, trozos de carbón, conchas de lapas, huesos de ovicápridos y un "chajasco" formado con vegetación de la zona. La cueva se abre en la parte alta de los riscos y, en la actualidad, es prácticamente inaccesible, a menos que se practique la escalada.
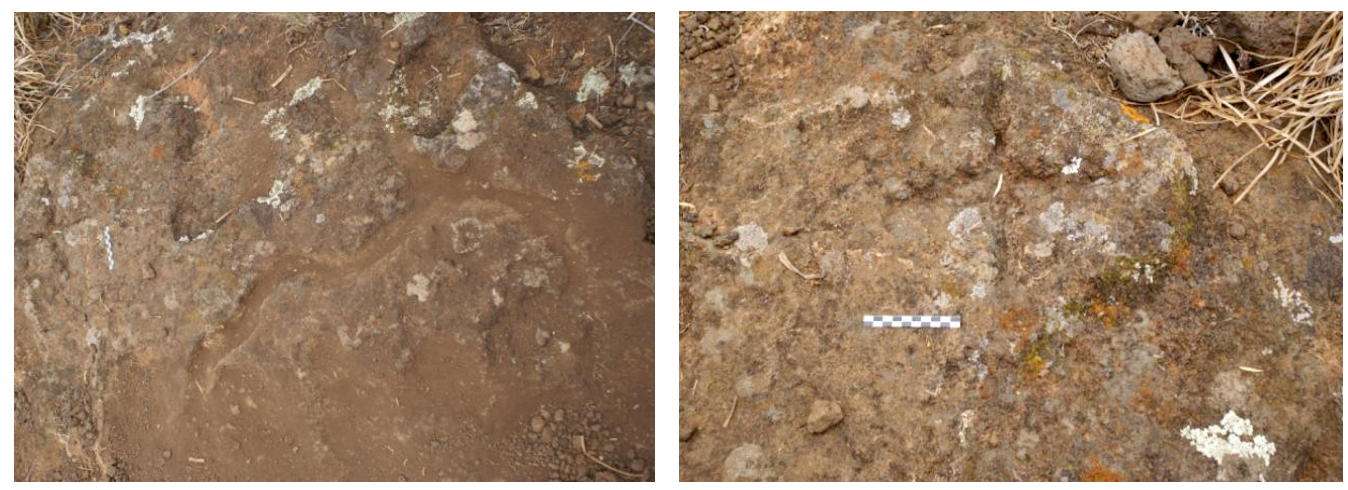

Figs. 2 y 3.

Tal y como comentamos en el párrafo anterior, en la parte superior del lomo que delimita la margen izquierda del Barranco del Espigón, nos encontramos con otros dos yacimientos que nos hablan de la importancia estratégica que tenía este lugar. Sin duda, el más espectacular de ellos es un posible almogarén, "casa santa", en el que nos encontramos con una pequeña covacha, canalillos y cazoletas de diferentes tamaños en horizontal y en vertical, un gran canalón central y hasta un pequeño petroglifo cruciforme. Todos estos elementos están grabados en una plancha de toba de unos 30 metros de largo por unos 10 metros de anchura. El único resto arqueológico superficial consistía en un fragmento de cerámica de gran tamaño de 
una vasija de la Fase I. La panorámica que se domina de los alrededores es muy amplia hacia los cuatro puntos cardinales.

Finalmente, a unos 100 metros hacia el este del almogarén descrito anteriormente localizamos un pequeño conjunto de canalillos y cazoletas (Fig. 2) emplazado en la parte superior del lomo y expuesto hacia el mar. El panel tiene como soporte una plancha de toba de quince por cuatro metros. Las cazoletas son circulares u ovales y están comunicadas por estrechos canalillos. Así mismo, también aparece un pequeño petroglifo cruciforme (Fig. 3). Los restos arqueológicos superficiales estaban formados por fragmentos de cerámica sin decoración, piezas líticas de basalto gris y trozos de conchas de lapas.

\section{La excavación de la necrópolis del Espigón}

Los trabajos de excavación se llevaron a cabo a mediados de la década de los 70 del siglo XX y, desgraciadamente, nunca se ha publicado un trabajo en condiciones sobre este importante descubrimiento. Es más, ni siquiera se sabe dónde están los diarios de excavaciones, así como parte del ajuar funerario, ni tampoco tenemos claro cuál habría sido la cavidad exacta que albergaría la momia (Fig. 4).

Fig. 4.

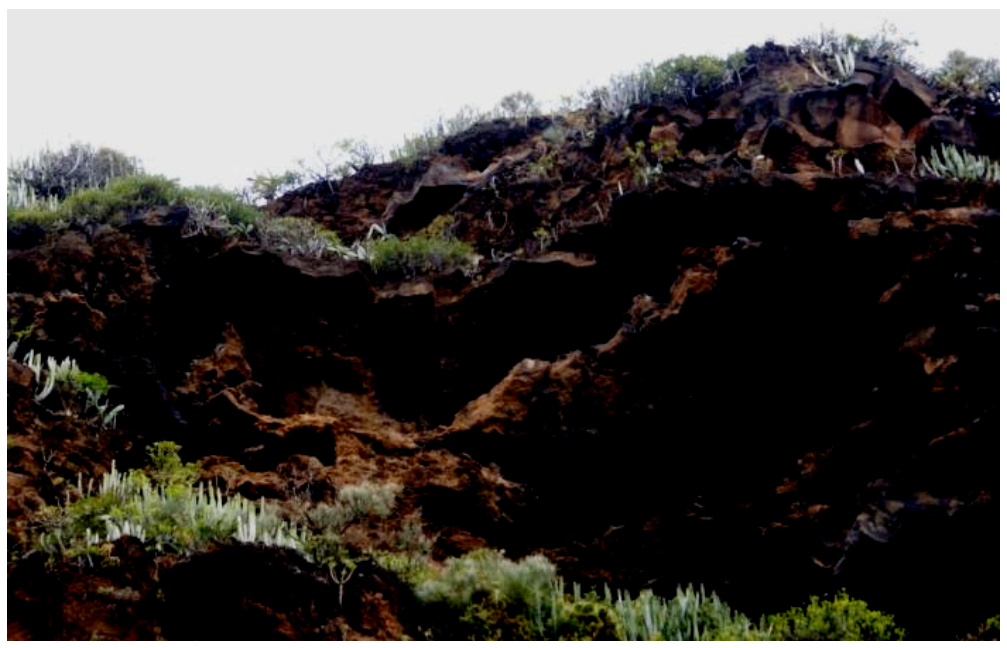

Los únicos datos conocidos, hasta la fecha, son las escasas líneas que transcribimos a continuación:

"(..) En esta cueva, bajo una fina capa de tierra mezclada con excrementos de aves se encontraron, sin conexión anatómica, restos óseos humanos pertenecientes a varios individuos, y al fondo de la cueva, y a un mismo 
nivel, los cadáveres que conservan restos de piel en algunas partes de su cuerpo. Aparecen cubiertos en parte por pieles de animales perfectamente curtidas y cosidas y atados con cuerdas vegetales. Uno de los cadáveres estaba en posición decúbito supino, y decúbito lateral flexionado el otro, el cual, cuando se inició la excavación, carecía de parte del tórax y de las extremidades superiores. Ambos descansaban directamente sobre el suelo rocoso, sobre el cual en algunas partes se habían colocado hojas de pino y de otras especies vegetales. El único ajuar que se les puede asociar son algunas "mocas". Se hallaron, además, en las proximidades de los restos humanos fragmentos cerámicos sin decorar, "mocas", patellas, punzones, un pequeño cuenco de madera y algunas ramas de palmera y de otros árboles, en ocasiones atadas con cuerdas vegetales." (M. Hernández Pérez, 1977).

A pesar de ser escueta la cita si es verdad que nos ofrece mucha información. En primer lugar nos habla de la existencia de depósitos primarios (cadáveres que conservan restos de piel en algunas partes de su cuerpo) y depósitos secundarios (sin conexión anatómica, restos óseos humanos pertenecientes a varios individuos). El primero de los depósitos correspondería a aquellos cuerpos que son aportados en estado fresco o después de acontecido el fallecimiento a su lugar definitivo y que como norma son reconocibles mediante la documentación de la persistencia de las conexiones y relaciones anatómicas primarias. Por el contrario, los secundarios, o más exactamente, las sepulturas en dos o más tiempos, son aquellos en los que el depósito de los restos humanos ha sido precedido por una fase de "descarnamiento" activo o pasivo que se desarrolla en un lugar diferente al lugar en el que los documenta la intervención arqueológica. En términos generales, en este tipo de depósito se constata la pérdida parcial o total de conexiones anatómicas en el esqueleto (J. Velasco Vázquez, T. N. Ruíz González, S. Sánchez Perera, 2005).

La posición de los cuerpos era decúbito supino y decúbito lateral flexionado. El primero de los casos es el ejemplo que más se repite entre las momias existentes en Canarias variando únicamente la posición de las manos, ya sea colocándolas hacia los muslos como se aprecia en la momia guanche localizada en el Museo Antropológico de Madrid, o sobre el pubis o el vientre como se aprecia en la momia guanche de Cambrige. La posición decúbito lateral flexionado no es tan común pero si contamos con otros ejemplos en otras islas.

La cita anterior nos aporta otro dato muy interesante que nos habla que los cuerpos estaban sobre el suelo rocoso (ambos descansaban directamente sobre el suelo rocoso, sobre el cual en algunas partes se habían colocado hojas de pino y de otras especies vegetales) y es que las crónicas de los primeros que llegaron a las islas Canarias nos señalan que los Benahoarita, cuando morían y 
eran depositados en las cuevas, éstos no podrían tocar el suelo tal y como nos señala Abreu Galindo en el siguiente relato:

"Era en enfermedad esta gente muy triste (los antiguos palmeros). En estando enfermo, decía a sus parientes: - Vacaguare ("quiérome morir"). Luego le Ilenaban un vaso de leche y lo metían en una cueva, donde quería morir, y le hacían una cama de pellejos, donde se echaba; y le ponían a la cabecera el gánigo de la leche, y cerraban la entrada de la cueva, donde lo dejaban morir. Todos se enterraban en cuevas, y sobre pellejos, porque decían que la tierra ni cosa de ella no había de tocar al cuerpo muerto".

\section{Las momias de la Necrópolis del Espigón}

Aunque en el apartado anterior ya hemos dado algunas pinceladas sobre la posición de las momias y características de los depósitos localizados en el Espigón, ahora nos centraremos en el proceso de momificación y en las características bioantropológicas de las dos momias localizadas en Puntallana.

Lo primero que hay que destacar es que no sabemos si para el caso de La Palma, los restos eran momificados fruto del trabajo del hombre, o si por el contrario, se producía una momificación natural. Para la isla de Tenerife y de Gran Canaria (Fig. 5, 6 y 7) sí que tenemos referencias sobre la existencia de la práctica del mirlado o proceso de embalsamar los cadáveres produciendo un cuerpo momificado al que se le denominaba xaxo.
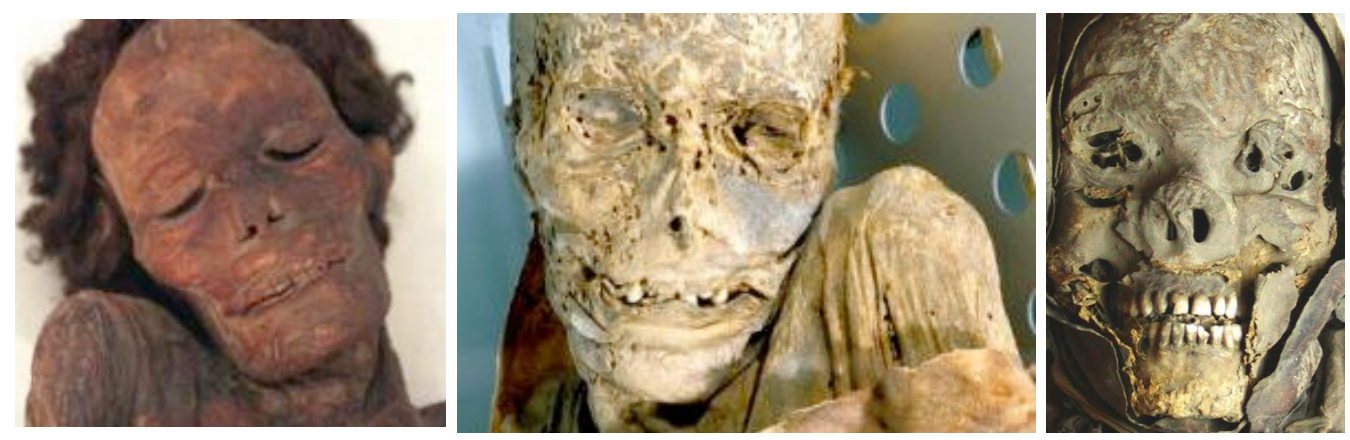

Figs 5,6 y 7 .

Así pues, una vez más Abreu Galindo nos señala lo siguiente:

"Cuando morían, tenían esta costumbre y orden en sus entierros, que había hombres y mujeres que tenían oficio de mirlas los cuerpos, y a eso ganaban 
su vida, desta manera que, si moría hombre, lo mirlaba hombre, y la mujer del muerto le traía la comida; y si moría mujer, la mirlaba mujer, y el marido de la difunta le traía la comida; y servían éstos de guardar el cuerpo difunto, no lo comieran los cuervos y guirres y perros. Y la manera de mirlar los cuerpos era que llevaban los cuerpos a una cueva y los tendian sobre lajas y les vaciaban los vientres, y cada día los lavaban dos veces con agua fría las partes débiles, sobacos, tras las orejas, las ingles, entre los dedos, las narices, cuello y pulso. $Y$, después de lavados, los untaban con manteca de ganado y echábanles carcomas de pino y de brezo y polvos que hacían de piedra pómez, porque no se dañasen. $Y$, estando el cuerpo enjuto sin ponerle otra cosa, venían los parientes del muerto, y con cueros de cabras o de ovejas sobados los envolvían y los liaban con correas muy luengas, y los ponían en las cuevas que tenían dedicadas para ello, cada uno para su entierro; y esto tenían los inferiores del rey, que donde quiera que morían, se enterraban en su cueva que tenían para su sepultura; pero el rey, donde quiera que moría, lo habían de llevar a su sepultura, donde tenían sus pasados; a los cuales ponían por su orden, para que se conociesen; y así los ponían fajados y sin cubrirles con cosa encima"

Es decir, según el cronista, la momificación guanche pasaba por una serie de procesos: el lavado, la evisceración, el uso de plantas aromáticas y otros elementos, la desecación y la envoltura del muerto, durando este proceso al menos quince días (M. Álvarez, I. Morfini, 2014). De todo lo señalado, el punto más controvertido es sobre la evisceración ya que no se ha hallado prácticamente ninguna momia con restos de cortes en el abdomen para extraer los órganos pero sí que es verdad que en el interior del cuerpo se han encontrado sustancia vinculadas con un posible tratamiento y que tuvieron que haber sido introducidas sin incisiones.
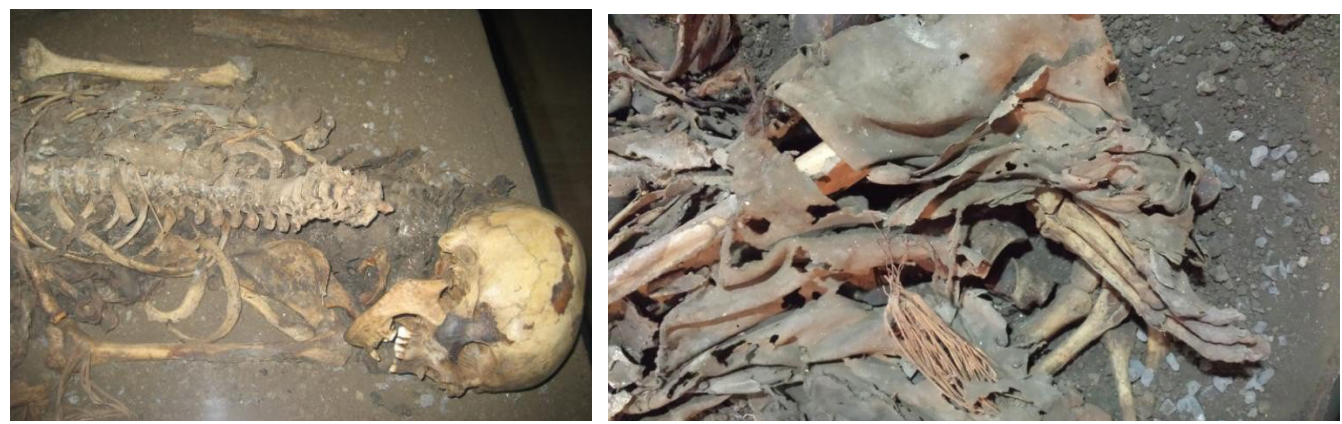

Figs. 8 y 9. 
Para el caso del Espigón y como ya señalamos en líneas superiores no se puede corroborar ni negar que haya sufrido un proceso de momificación antrópica. Hoy en día estos restos prácticamente no parecen momias propiamente dichas ya que han sufrido un deterioro importante por el mal cuidado de ellas hasta su traslado al Museo Arqueológico Benahoarita (Mab).

La momia principal (Fig. 8) se trata de un individuo, probablemente masculino, de aspecto grácil. Aproximadamente tendría 35 años de edad según el estudio de la dentición (A. Meiln et al. 2007). Junto a ella, aparecieron las extremidades inferiores de otros restos momificados, adulto, decúbito lateral flexionado que destaca por presentar una patología no definida en uno de sus fémures (Fig. 9). El estudio de este material se muestra complejo ya que se encuentra en una atmósfera protectora que impide su análisis en profundidad.

La momia del Espigón ${ }^{5}$ presenta una serie de patologías sin contar las dentales que serán expuestas a continuación: se aprecian pequeños golpes en el cráneo así como una posible fractura de tabique nasal. Los restos decúbito lateral flexionados también presentan una patología difícil de interpretar (Fig. 10). Inicialmente pensamos que se trataba de una fractura sin fusionar que produjo una excrecencia ósea en torno al hueso dañado. Sin embargo, tras consultarlo con varios investigadores, éstos nos han señalado que podría tratarse de un tumor. Sin embargo, hasta que no se puedan manipular los restos no se podrá saber a ciencia cierta.

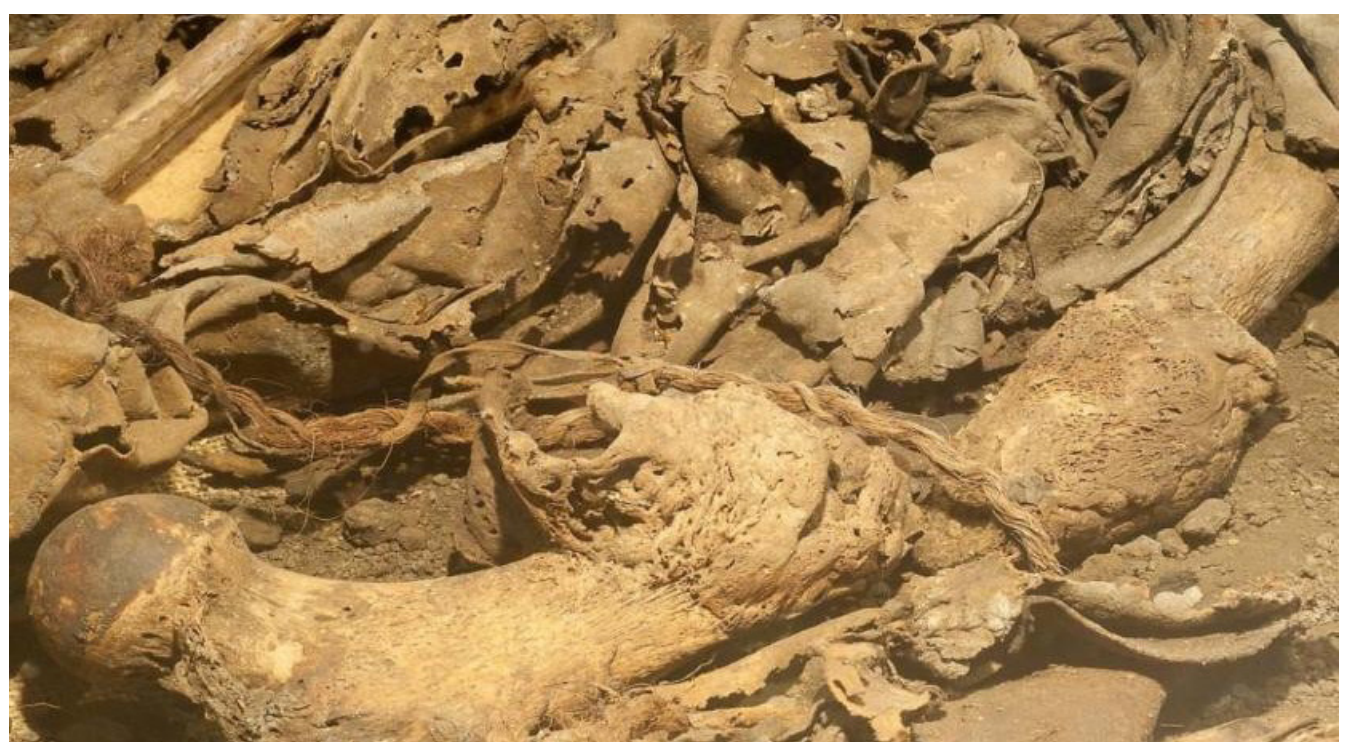

Fig. 10.

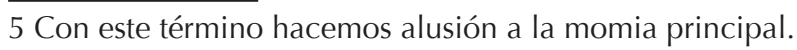


Estos restos, al igual que hemos podido apreciar en los relatos antiguos y en imágenes superiores, también fueron envueltos con pieles de animales (Fig. 11 y 12). De hecho, tras estudios científicos efectuados por la Universidad Pompeu Fabra de Barcelona, han señalado que la piel empleada para esa misión era de ciervo, algo bastante curioso si tenemos en cuenta que los animales existentes en la isla de La Palma en época aborigen eran las cabras, las ovejas y los cochinos. Este descubrimiento solo se puede interpretar de dos formas: o bien la piel de ciervo fue traída cuando los Benahoarita llegaron desde las costas africanas a La Palma o, por el contrario, se trata de una contaminación de la muestra analizada.
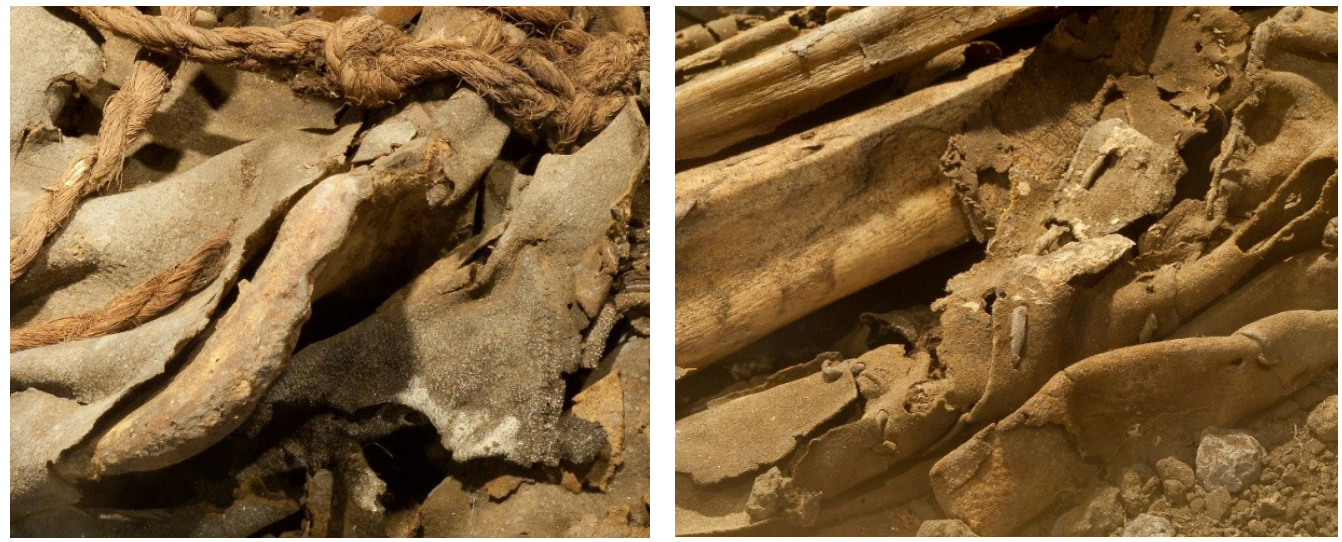

Figs. 11 y 12.

\section{Sobre los otros ocupantes de la Necrópolis del Espigón}

Centrándonos ya en los restos humanos esqueletizados, la única cita con la que contamos sobre la excavación del enclave funerario habla de que "(...) en esta cueva, bajo una fina capa de tierra mezclada con excrementos de aves se encontraron, sin conexión anatómica, restos óseos humanos pertenecientes a varios individuos", en su mayoría esqueletizados. Tras un estudio preliminar ${ }^{6}$, se han localizado al menos, restos de quince individuos, siendo los fémures, húmeros y tibias derechas las que nos ha dado el número mínimo de individuos. Destacan las costillas como las más numerosas seguidas muy de cerca por las vértebras (setenta y nueve cervicales, ciento treinta dorsales y sesenta y dos lumbares). Posteriormente nos encontraríamos con las falanges proximales de las manos y de los pies, clavículas, húmeros...etc. (N. Álvarez Rodríguez, 2011).

6 Hay que señalar que estos son resultados preliminares ya que una parte de los materiales bioantropológicos se encuentran actualmente en los fondos del Museo Arqueológico Benahoarita (Mab) y otros en los almacenes de la Universidad de La Laguna. Es por ello que las conclusiones todavía están pendientes de revisión. 
Con respecto a la existencia de cráneos o mandíbulas, en los fondos del Mab solo contamos con el propio cráneo de la momia pero si tenemos constancia de la existencia de al menos tres cráneos y nueve mandíbulas de las cuales, una es de un individuo infantil. Poca información se puede añadir sobre la determinación de la edad y el sexo debido a que los restos, actualmente no forman parte de los fondos del Mab.

El estado de conservación de los materiales, en su conjunto, es bueno. Para ello, cuando fueron analizados los restos, se les aplicó tres categorías consistentes en bueno, regular y malo según su estado de fragmentación. El resultado fue el siguiente: el $72,5 \%$ responde a huesos en un buen estado de conservación, el 10,9\% presenta un estado regular y por última, el 10,3\% están muy fragmentados.

Si hablamos sobre el sexo y al igual que sucede con la edad, nos encontramos con un problema muy grave a la hora de abordar este tipo de materiales. Los restos no fueron individualizados tras su excavación. Simplemente nos encontramos con un amasijo de huesos dividido en cajas según su tipología. Es por ello que solo podemos saber el sexo y la edad de algunos fragmentos óseos y no de un esqueleto completo. A partir de lo mencionado y excluyendo los restos momificados, los coxales que se conservan suficientemente completos para darnos información sobre el sexo nos indican, que posiblemente cinco pertenecieron a individuos femeninos y cinco a individuos masculinos (J. E. Buikstra y D. H. Ubelaker, 1994). Si analizamos las mandíbulas según su morfología, podríamos decir que de los nueve maxilares inferiores, posiblemente tres pertenecerían a individuos femeninos y cinco individuos masculinos. (W. N. Krogman e M. Y. Iscan, 1986). La novena mandíbula pertenece a un individuo infantil (Fig. 13).

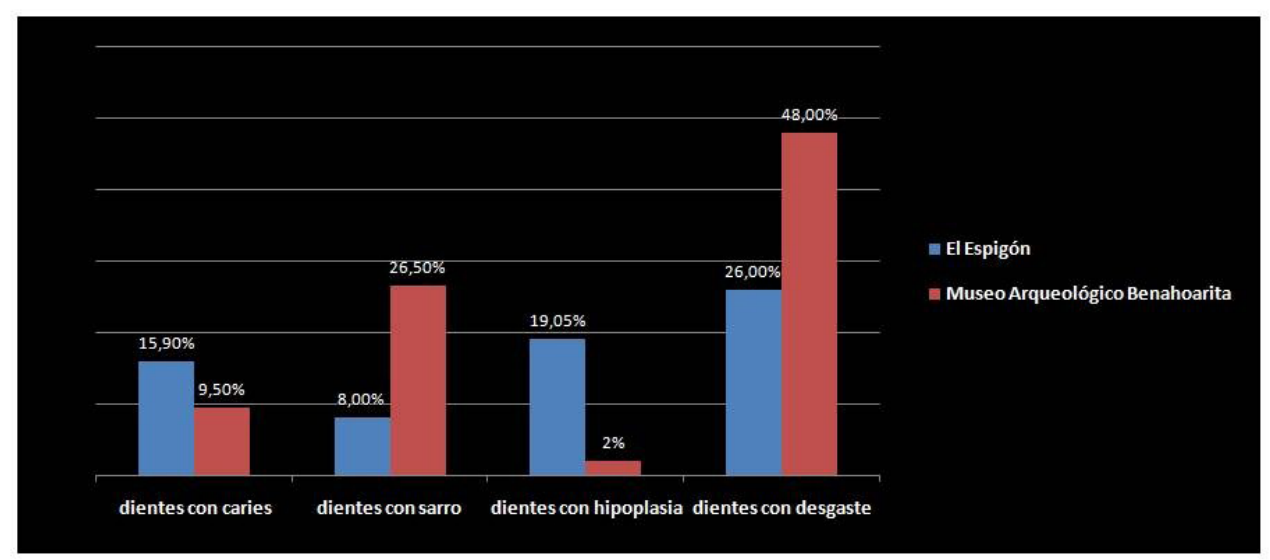

Método de Registro: Chimenos et al. “Propuesta de protocolo de valoración de porómetros en Poleodontologí". 2001

Fig. 13. 
La presencia de individuos no adultos es un hecho importante ya que, para la isla de La Palma se conocen muy pocos casos. Esto no quiere decir que la mortalidad infantil fuera reducida entre los Benahoaritas, simplemente nos indica que la presencia de individuos infantiles en el registro arqueológico no ha sido estudiado porque no se ha efectuado una excavación en condiciones en un yacimiento funerario. La mayoría de los restos humanos que se localizan en los fondos del Mab provienen de sucesivos expolios y saqueos de las necrópolis produciendo este hecho un grave desconocimiento que se refleja, entre otros casos, en el desconocimiento de ciertos campos como podría ser este

Además de estos individuos, nos encontramos restos tanto de juveniles, como de adultos y de seniles, por lo que está presente en la necrópolis todos los grupos de edades, algo muy interesante para efectuar en el futuro estudios de paleodemografía (Brothwell, 1987).

Con respecto a las patologías, tras un estudio inicial y sin incluir ahora mismo las enfermedades bucales ${ }^{7}$, las vértebras son las que presentan el mayor porcentaje de patologías (tabla 1) asociadas a enfermedades articulares degenerativas como la artrosis afectando tanto a las carillas articulares como a los cuerpos vertebrales (D. Campillo, 2004). En muchos casos se produjo la fusión de varias vértebras. El $38,4 \%$ afecta a las facetas articulares y el $48,1 \%$ a los cuerpos vertebrales de las cervicales, el $48,3 \%$ afecta a las facetas articulares y el $18,3 \%$ a los cuerpos vertebrales de las dorsales y el $65 \%$ afecta a las facetas articulares y el $52,5 \%$ a los cuerpos vertebrales de las lumbares. En conclusión, las cervicales como las lumbares se verían afectadas por la existencia de osteofitos de mayor o menor índole siendo su porcentaje alto mientras que las dorsales destacarían por la presencia de un mayor porcentaje de porosidad.

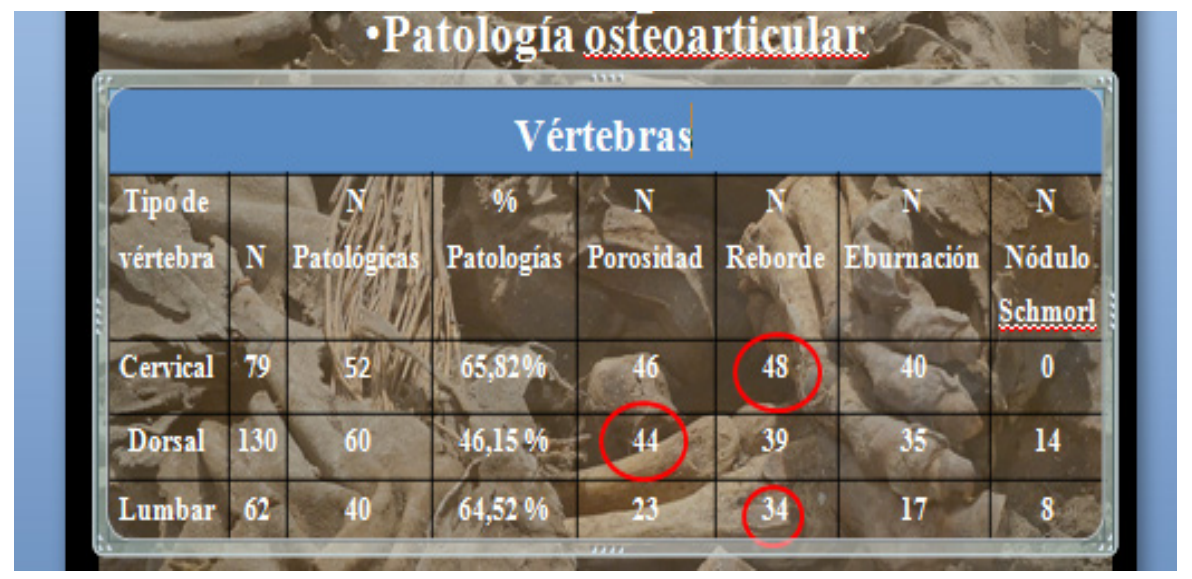

Tabla 1.

7 En el apartado siguiente serán mencionadas. 
Hay que señalar que la artrosis o enfermedades degenerativas también se observan en otros huesos como sucede en húmeros, clavículas, escápulas, etc. Ilegándose a apreciar tanto porosidades como formaciones de osteofítos o incluso eburnaciones.

\section{Estudio de la dentición}

El análisis dentomaxilar se ha realizado en la única muestra disponible de cráneo localizado en los fondos del Mab y cincuenta piezas dentarias descontextualizadas y no asociadas a ningún individuo concreto. El número de objetos de estudio de la muestra no responde a la aleatoriedad que permitiría un estudio de inferencia estadística que permita llegar a conclusiones generalizadas sobre El Espigón, y menos sobre las posibles características de los antiguos pobladores de esta zona de La Palma. A pesar de esta circunstancia, el análisis descriptivo de las características anatomopatológicas dento-maxilares de los restos disponibles aporta detalles que permiten ir realizando hipótesis sobre las que sustentar posteriores estudios.

El cráneo se apoya en latero versión sobre el esplacnocráneo izquierdo. En líneas generales, y en base solamente al estudio dentomaxilar, la estimación inicial superficial indicaría que estamos antes un individuo varón de una edad estimada de más de 35 años. El estado dental de este individuo es el que sigue.

Existencia de restos radiculares del 17, alteración de origen antemortem y asociada a una reabsorción ósea apical de origen odontogénico con fistulización ósea evidente. En principio habría que asumir que la alteración de este molar no parece debida de manera primaria a caries, sino a la destrucción producida por un gran grado de atrición o desgaste con posterior alteración cariogénica. Esta conclusión viene apoyada en la abrasión generalizada de las piezas presentes en el individuo objeto de estudio y en la ausencia aparente de caries. Presenta también ausencia de origen postmortem de 12, 11, 21, 23, 35, 34, 32, 31, 41, 42, 43, 44, 45. Se aprecia asimismo la ausencia de las piezas 24 a 28.

Parece vislumbrarse cierta reabsorción ósea con desaparición de los lechos alveolares que podrían indicar pérdidas anteriores al momento de la muerte, pero debido a la imposibilidad de la exploración apropiada (la muestra se encuentra en una urna) es difícil aseverar este hecho. En principio, y en las condiciones de observación antes descritas, no se observan caries - al menos grandes cavidades cariogénicas - en las piezas presentes en la muestra de este cráneo. A nivel de 36,37 y 46 se observa reabsorción de hueso periodontal, con ligera exposición de furca a nivel del 36 y sendas reabsorciones de la lámina vestibular de las raíces mesiales de ambas piezas (E. Chimenos, et al, 1999).

Destaca el hecho de un gran grado de abrasión dental oclusal (G. Turner et al., 2013), este desgaste no sólo se aprecia a nivel de las superficies masticatorias de los molares presentes, sino también en el canino permanente superior derecho 
(13). Esta circunstancia, junto con la reabsorción ósea alveolar periodontal concomitante, manifiestan un trauma oclusal importante, destacado indicador de estrés debido a factores ambientales y nutricionales; y defendido por algunos autores como variable de estudio a la hora de conocer la edad del individuo

Se aprecia así mismo la pérdida de esfericidad y un marcado aplanamiento del cóndilo mandibular derecho. Esta alteración parece ser más debida a causas de estrés funcional que a alteraciones óseo-degenerativas. El cóndilo izquierdo no se puede estudiar adecuadamente (M. Oxenham, 2006).

Se describen a continuación, de manera agregada, las piezas dentales provenientes de este yacimiento y disponibles para el estudio. Es evidente que las conclusiones a las que se podría llegar tras el análisis de este conglomerado de restos, totalmente descontextualizados en lugar y en tiempo, no soportan un análisis científico completo, pero ayudan a marcar próximas líneas de trabajo.

El conjunto de piezas dispersas está compuesto de cincuenta y tres dientes en diferente estado de conservación. De manera muy somera y sin hacer distinciones por cuadrantes, la descripción conjunta es la que sigue: catorce premolares, diez molares, cinco caninos, diecinueve incisivos: todas estas piezas permanentes. Existen también un canino y tres incisivos deciduos.

De todas estas muestras, existe caries en ocho de ellas. Aparecen además nueve molares con un grado avanzado de desgaste, doce piezas con hipoplasia y cinco con sarro (M. P. Alfonso et al., 2005).

Es interesante el análisis de las piezas temporales. En base a los restos óseos postcraneales asociados a este yacimiento, asumimos que pertenecen a un solo individuo. Basándonos en el desarrollo radicular de los incisivos y del canino, en la exploración bajo microscopio de las ligeras facetas de desgaste del canino temporal y aplicando en el conocido esquema de Schour y Massler, podemos estimar la edad de la muerte de este individuo en 4 años ( \pm un año).

Debido a que no existe una memoria descriptiva de las excavaciones, tenemos que asumir también que algunas de las piezas dispersas, pertenecientes al conjunto de restos dentales descritos someramente en los párrafos anteriores, pueden pertenecer a la conocida como "Momia de El Espigón".

No se aprecian hipoplasias marcadas en las piezas dentarias implantadas en el alveolo de la momia, aunque sería necesaria una mejor exploración, debido a las limitaciones que impone la urna protectora (A. H. Goodman, et al., 1980).

Asumiendo los obstáculos antes reseñados para un razonamiento deductivo científico, si consideramos que es factible plantear una hipótesis diferenciadora basada en estos hallazgos, en cuanto a la comparación de las piezas dentales "dispersas" y las presentes e implantadas en el lecho alveolar. Parece razonable pensar - con las precauciones metodológicas ya recalcadas previamente - que las piezas dentarias presentes en el individuo "momia" presentan un bajo nivel de 
caries, un mayor grado de atrición dental y menos hipoplasia ,comparativamente hablando, con respecto al conglomerado de piezas "esparcidas".

Se ha realizado además un estudio descriptivo del estado dental de las piezas del yacimiento de El Espigón y del resto de las piezas dentales que se encuentran en el Museo Arqueológico Benahoarita. Es conveniente advertir, de nuevo, que esta comparación nos sirve, por ahora, solamente para establecer hipótesis que luego deben ser comprobadas en investigaciones posteriores siguiendo más fehacientemente el método científico.

Como se puede apreciar en la siguiente gráfica, a nivel meramente descriptivo existen diferencias en algunos aspectos del estado dental al hacer la comparación entre ambos grupos de muestras (piezas de El Espigón y el resto de las piezas del Museo Arqueológico Benahoarita), sobre todo en el porcentaje de caries, sarro, hipoplasia y desgastes. Sería deseable ahondar aún más en estas aparentes diferencias en futuras excavaciones, pues de confirmarse implicarían interesantes contrastes de patrones en el ámbito cultural, nutricional y paleoepidemiológico.

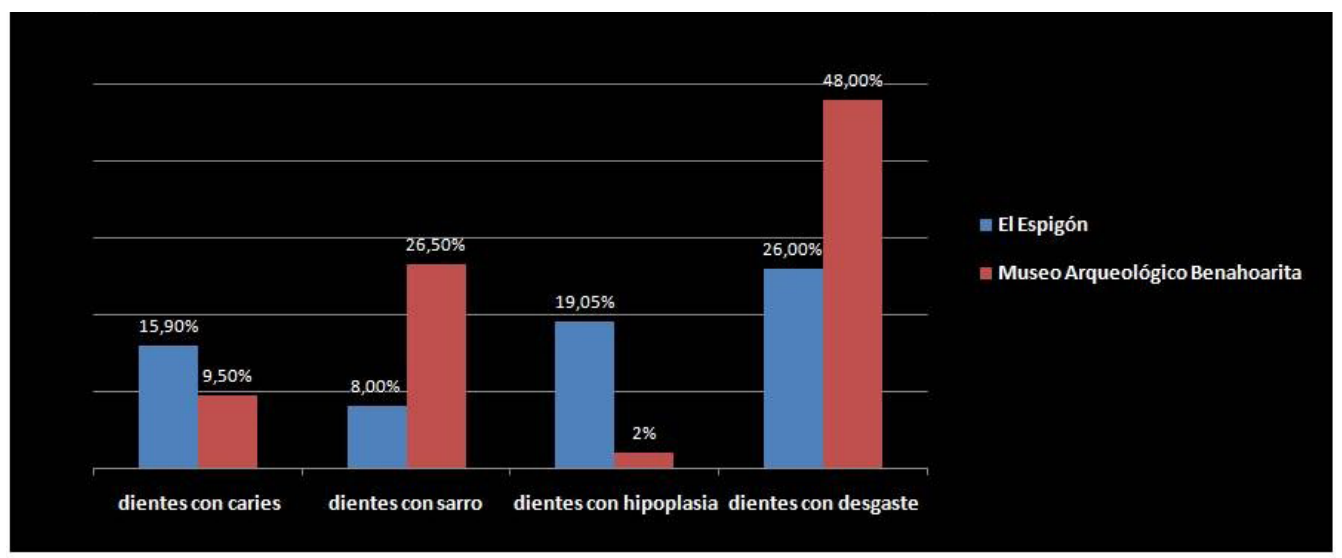
Método de Registro: Chimenos et al. "Propuesta de protocolo de valoración de
parómetros en Paleodontologia". 2001

Gráfica 1: Porcentaje entre las patologías existentes en El Espigón y las piezas que se localizan en las muestras del Mab"

\section{Conclusión}

Este trabajo preliminar se muestra como punto de partida de futuras investigaciones que permitirán revelar como vivieron y como murieron los 
antiguos pobladores del yacimiento de El Espigón dentro del cantón de Tenagua (municipio de Puntallana). Lo que tenemos claro con este pequeño estudio es que el Barranco de El Espigón fue un sitio optimo para que un conjunto de individuos, vinculados, probablemente, por lazos familiares, pudieran obtener todos los recursos necesarios para vivir. Las patologías vertebrales y la dentición nos ayudan a entender un poco más sus formas de vida. Así pues, de las vertebras podemos deducir que los benahoaritas probablemente realizarían actividades donde la cabeza era empleada para llevar carga encima provocando, un muchos casos, una reducción de los cuerpos vertebrales por aplastamiento, algo visible en otras islas del Archipiélago Canario. Por su parte, los dientes nos hablan de una dieta muy abrasiva debido a los desgastes presente. Hay que señalar que los aborígenes Canarios empleaban para molturar los cereales molinos de piedras. En definitiva, estamos ante una de las pocas necrópolis de la isla de La Palma donde se entre mezclan los restos momificados y esqueletizados.

\section{Bibliografía}

J. ABREU GALINDO: Historia de la Conquista de Las Siete Islas de Canarias. Editorial Goya. 1977.

M. P. ALFONSO et al: "Reevaluating Harris Lines - A Comparison Between Harris Lines and Enamel Hypoplasia". Coll. Antropol. 29 (2005) 2: 393-408

N. ÁLVAREZ RODRIGUEZ: "Estudios de Arqueología funeraria y bioantropología en la Isla de la Palma. Un estado de la cuestión". Estudios generales de la Isla de la Palma. Revista número 5. 2011

M. ÁLVAREZ SOSA, I. MORFINI: Tierra de Momias. La técnica de eternizar en Egipto y Canarias. Le Canarien. 2014

D. R. BROTHWELL: "Desenterrando huesos". Fondo de cultura económica. 1987.

J. E. BUIKSTRA, D. H. UBELAKER (eds.): "Standars for data collection from human skeletal remains". Proceeding of a Seminar at The Field Museum Natural History Organized by Jonathan Hass. Serie $\mathrm{n}^{\circ} 44$.

E. CHIMENOS et al: "Propuesta de protocolo de valoración de parámetros en Paleodontología". Gaceta Dental, 102:44-52. 1999

D. CAMPILLO et al: "Antropología física para arqueólogos". Ariel. 2004

A.GOODMAN et al: "Enamel Hypoplasias as Indicator of Stress in Three Prehistoric Populations from Illinois". Human Biology. Vol 52. No 3, pp 515-528. 1980.

W. M. KROGMAN, M. Y. ISCAN: "The Human Skeleton in Forensic Medicine". Charles C. Thomas Publisher, Springfield, Illinois, Usa. 1986. 
A.MEINL et al: "Comparison of the validity of three dental methods for estimation of age at death". International Journal of Forensic Science. 2007

M. OXENHAM et al: "Frequency, Location, Morphology and Aetiology of Osseous Mandibular Condylar Concavities". Int. J. Osteoarchaeol 16:517527. 2006

J. PAIS PAIS, A. TEJERA GASPAR: "La religión de los benahoaritas" .Santa Cruz de La Palma: Fundesculp. 2010.

G. TURNER et al: "Occupational Dental Abrasion from Medieval Kent". Int. J. Osteoarchaeol. 13: 168-172 (2003)

J. VELASCO VÁZQUEZ, T. N. RUÍZ GONZÁLEZ, S. SÁNCHEZ PERERA: El lugar de los antepasados. La necropolis bimbape de montaña la Lajura. El Hierro. 2005. 